\title{
Policy-Making for Households Appliances-Related Electricity Consumption in Indonesia- A Multicultural Country
}

\author{
Muhammad Ery Wijaya*, Tetsuo Tezuka \\ Department of Socio-Environmental Energy Science, Graduate School of Energy Science, Kyoto University, Kyoto, Japan \\ Email: *ery_wijaya@mail.ugm.ac.id
}

Received February 12, 2013; revised April 23, 2013; accepted May 14, 2013

Copyright (C 2013 Muhammad Ery Wijaya, Tetsuo Tezuka. This is an open access article distributed under the Creative Commons Attribution License, which permits unrestricted use, distribution, and reproduction in any medium, provided the original work is properly cited.

\begin{abstract}
Household energy consumption is strongly influenced by culture. Therefore, the study of the influence of culture on energy consumption is important for designing the most suitable energy conservation policy to increase society's adaptation to policy. The present paper has the following aims: 1) to analyze and compare decision-making in the use of electrical appliances; and 2) to compile a strategy to improve the adoption of higher-efficiency appliances and the wise use of electricity in Indonesia to optimize households' energy conservation. All aims are in the framework analysis of the different cultural backgrounds and ethnicities represented by two cities-Yogyakarta and Bandung. The finding indicates that people in Yogyakarta show greater awareness of the benefits of adopting higher-efficiency appliances than people in Bandung. Therefore, the awareness rate of energy consumed by appliances and energy efficiency of appliances is significantly higher in Yogyakarta. This study shows the integration of intervention strategy in the purchase and use of electrical appliances with regard to the consumers' decision and behaviors within a framework of the local culture to manage electricity consumption in the household sector.
\end{abstract}

Keywords: Household; Energy Efficiency; Energy Saving; Decision-Making

\section{Introduction}

Household energy consumption has been studied in many countries, as it typically accounts for a large percentage of the total energy consumption [1]. Understanding the characteristics of household electricity consumption is important for researchers and policy-makers who are concerned with the impact of households on electricity use and the environment. Therefore, there is an urgent need to raise the awareness that energy use and its impact on the environment should concern all individuals in their daily activities.

Household energy consumption is strongly influenced by cultural factors [2-7]. Lutzenhiser [8] argued that there is a need to understand the relationships between human groups (culture, ethnics or races) and their technologies and that these relationships can be used to account the frequencies and magnitudes of energy flows. The study also compiled several energy research studies and found that the cultural approach in energy consump-

${ }^{*}$ Corresponding author. tion and policy-making has promising applications on three levels: the descriptive, explanatory and predictive analysis of specific applications of energy consumption and conservation. Energy-use patterns and the resulting energy policy implications vary by cultural background. Thus, the study of the influence of culture on energy consumption is important for designing the most suitable energy conservation policy to improve society's adaptation to policy. However, the development energy policy model based on cultural approaches has been hampered by a lack of empirical research.

The Indonesian society consists of different cultural backgrounds or ethnic groups, which can be distinguished into several regions. The variety of cultural backgrounds may affect the residents' decision-making behavior in the purchase and use of electrical appliances in Indonesia. Our previous study found that the differences in electricity consumption patterns between two different cultural backgrounds were influenced by several driving factors, such as income, duration of time at home, and family size [9]. However, further comprehensive study of 
the techno-socioeconomics of electricity consumption under different cultural backgrounds should be conducted. Therefore, we investigated the influence of cultures in the decision-making process in the purchase of electrical appliances in both cities [10]. The factors influencing the purchase of appliances indicated that people in Yogyakarta show a greater awareness of the benefits of adopting higher-efficiency appliances than do persons in Bandung. This variation stems from cultural aspects that reflect the way that people consider factors in the purchase of appliance.

The current study examines the influence of cultural backgrounds on Indonesian household electricity consumption within the perspective of electricity consumers' choice determinants in the purchase of electrical appliances and decision-making in consuming electricity. All aims in this study are in the framework analysis of different cultural backgrounds and ethnicities. Two cities are selected to show the influence of culture on electricity consumption, Yogyakarta is a center of Javanese culture and Bandung represents Sundanese culture. This paper has the following aims: 1) to analyse and compare decision-making in the use of electrical appliances; and 2) to compile a policy strategy in Indonesia to improve the implementation of energy conservation through the wise use of electricity and the adoption of higher-efficiency appliances as found in previous study [10]. The results of this study are expected to improve the strategy and effort to design an energy conservation policy based on local cultures to improve the success of policy implementation.

\section{Overview of Indonesia}

\subsection{Indonesian Economy and Electricity}

Indonesian economic development boosts the industrial and commercial sector and the people's welfare. During the years 2001 to 2009, the GDP per capita increased sharply, with an average of $15 \%$ annually. The GDP per capita amounted to US\$ 748 in 2001 and US\$ 2698 in 2009 [11,12]. This trend is predicted to continue over the coming years due to the revival of the world economy. The largest economic activity in Indonesia is centralized in the Jawa-Madura and Bali areas, known as the JaMaLi area. In 2010, the total population in this area was 141 million people, or nearly $60 \%$ of country's total population [13]. The total electricity consumption was 79 TWh in 2000 and increased to 135 TWh in 2009 [11]. Nearly $78 \%$ of this consumption was in the JaMali area. In 2009, the national electrification ratio reached $63.75 \%$, and this value will continue to grow rapidly following national economic growth [14]. In the JaMaLi area, the industrial sector consumes the largest proportion of electricity (47\%), followed by the household sector (39\%) [15].
Although the industrial sector is the largest electricity consumer, the household electricity consumption tends to increase. Predictions suggest that by 2027, the household sector will be the largest electricity consumer in the JaMaLi area. According to the government's projection, the household sector will take $59 \%$ of the total electricity consumption share, whereas the commercial, industry and public sectors will consume $22 \%, 12 \%$ and $7 \%$, respectively [15]. Thus, households are an important group when addressing energy conservation. An additional reason to focus on households is that electricity consumption in households continues to rise

\subsection{Demography of Indonesia}

Indonesia is a multi-ethnic society with more than 1000 ethnic/sub-ethnic groups. Nevertheless, only 15 groups have more than 1 million people. According to Lietar and De Meulenaere [16], definition of ethnic group refers to a cultural identity that involves language, beliefs, morals, laws, tradition and patterns of behavior. According to the 2000 Population Census, published by Statistics Indonesia, the two largest ethnic groups in Indonesia, the Javanese and Sundanese, accounted for $41.7 \%$ and $15.4 \%$ of the national population, respectively [17]. Therefore, Sundanese and Javanese people which the populations are located on Java Island were the largest electricity consumers in Indonesia.

\section{Household's Behavior on Electricity Consumption}

A high percentage of household energy consumption is associated with the use of major household appliances. Genjo [4] investigated the relationship between possession of home appliances and electricity consumption in Japanese households. The study found that the increase in the consumption of residential electricity was due to the use of a greater number of home appliances. Therefore, efforts to promote energy savings in the household sector are continuously increasing. The energy efficiency of electrical appliances has significantly improved in recent years. The improvement in energy efficiency will impact the overall energy demand and, subsequently, the environment [18]. However, these newly developed efficient appliances will not be widely used unless societies actively adopt them. The improvement in energy efficiency does not necessarily lead to an overall decline in physical consumption due to inappropriate consumption practices.

Guerin [19] summarized numerous studies of household energy consumption and found that the variables that most frequently affected energy behavior and consumption were occupant characteristics, occupant attitudes and occupant actions. However, a few studies have in- 
vestigated energy consumption from the consumers' perspective. Yamamoto [20] investigated decision-making concerning electrical appliance use in Japan. The study found that the price did not function as a decisionmaking signal for electrical appliance users. Rather, decision-making was dependent on the characteristics of particular electrical appliances and the electricity payment system. Gaspar and Antunes [21] studied the consumer choice determinants in the purchase of appliances and analyzed the factors that drove the consideration of the energy efficiency class in Europe. Nevertheless, there is no comprehensive analysis that combines the consumer choice determinants in the purchase of appliances and behavior in the use of appliances in a framework to improve the energy conservation in the household sector.

Several researchers have studied household energy consumption as it relates to various population groups. Poyer [3] investigated differences in residential energy consumption between Latino and non-Latino households in the USA. The results showed significant variations in the patterns of energy consumption for Latinos and nonLatinos. Helbert [5] conducted a study on household energy consumption patterns in Guatemala and found that the energy portfolio of different ethnic groups significantly varied.

Nevertheless, there is no comprehensive analysis that combines the consumer choice determinants in the purchase of appliances and behavior in the use of appliances in a framework of different cultural backgrounds and ethnicities to improve the energy conservation in the household sector. To address these gaps, this study proposes to achieve energy conservation in the household sector with regards to its cultural backgrounds, both an increase in energy efficiency (through the adoption of higher-efficiency class appliance types) and the promotion of environmental consumer behaviors (through better use of electrical appliances) should be analyzed and promoted.

\section{Methodology}

Although an understanding of the technological use, social and economic characteristics of electricity consumers is important for improving energy conservation, it is not sufficient. Such knowledge should be complemented by the assessment of behavioral economics and human psychosocial variables such as attitudes, beliefs and perceived benefits in the purchase and use of electrical appliances. In fact, electricity consumption is affected not only by the use of electrical appliances but also by choice determinants of the efficiency of appliances upon purchase. However, few studies or projects have assessed electricity consumption based on cultural background. Particularly appliance attributes, psychosocial and socioeconomic variables have not been examined in an inte- grated manner with knowledge of technological choices and utilization. Hence, not all energy conservation policies that are currently practiced in the world may be applied in all societies. The present comprehensive study is designed to develop a policy framework that is suitable for society based on the influence of culture.

This research conducted a questionnaire survey in two cities. In Yogyakarta, only Javanese people were recruited as respondents. In Bandung, only Sundanese people were selected. The research was conducted from October to November 2011. The respondents were recruited through a door-to-door solicitation procedure in which they were asked to consent to a survey of their home appliances, review of their monthly electricity bill, and an in-depth interview regarding household members' typical electricity use behaviour. Approximately 30\% of households from both cities in this survey used a prepaid system for their electricity payment.

With several barriers during data collection, such as time and financial limitations. The total sample size was rounded to 100 respondents in each city according to the income level distribution. The selected sample was validated with the statistics of both cities published by Statistics Indonesia to avoid sampling bias. Details of respondents' profile were similar as defined in [10].

\section{Outline of the Questionnaire Survey}

The study investigated the following: 1) choice determinants of appliance purchases; and 2) decision-making in appliance use. Meanwhile, the questions and analysis concerning the choice determinants of appliance purchases were presented in our previous study [10].

The questions related to decision-making in the use of electrical appliances were centered on two aspects, attitude and knowledge and technological perspectives (see details at Table 1). The content of the questionnaire

Table 1. Questions related to decision-making in the use of electrical appliances.

\begin{tabular}{|c|c|c|}
\hline No. & Criteria & Question \\
\hline \multirow{5}{*}{1.} & \multirow{5}{*}{$\begin{array}{l}\text { Attitude and } \\
\text { knowledge }\end{array}$} & $\begin{array}{l}\text { How do you understand the electricity } \\
\text { prices? }\end{array}$ \\
\hline & & $\begin{array}{l}\text { How do you remember the monthly } \\
\text { electricity bill? }\end{array}$ \\
\hline & & $\begin{array}{l}\text { How do you remain aware of changes } \\
\text { in the monthly electricity bill? }\end{array}$ \\
\hline & & $\begin{array}{l}\text { How do you remain aware of the } \\
\text { change of the electricity prices? }\end{array}$ \\
\hline & & $\begin{array}{l}\text { How do the electricity payment } \\
\text { systems affect your awareness of the } \\
\text { monthly bill? }\end{array}$ \\
\hline \multirow{2}{*}{2.} & \multirow{2}{*}{$\begin{array}{l}\text { Technological } \\
\text { perspective }\end{array}$} & $\begin{array}{l}\text { How do you remain aware of the price } \\
\text { of electricity consumed by appliances? }\end{array}$ \\
\hline & & $\begin{array}{l}\text { How do you remain aware of the } \\
\text { energy efficiency of appliances? }\end{array}$ \\
\hline
\end{tabular}


covered the following: 1) knowledge of electricity prices; 2) memory of electricity payment; 3) awareness of the changes of electricity bill; 4) awareness of electricity consumed by electrical appliances; 5) awareness of the energy efficiency; 6) response to the change of electricity price; and 7) effects of payment system.

Respondents were provided many options related to the questions and rated their level of agreement or disagreement on a Likert scale. After receiving the responses from respondents, the average scores for every question were calculated. For each question, the option with the higher average score was the first-ranked option and so on. Additionally, to compare decision-making in the purchase and use of electrical appliances in the two cities, a $T$-test was employed.

\section{Results and Discussion}

\subsection{Analysis of Choice Determinants in the Purchase of Electrical Appliances}

In order to understand the choice determinants of electricity consumers in the purchase of electrical appliances, the summary of our previous study [10] is presented in this section.

\subsubsection{Use of Appliances}

The replacement of an old electrical appliance with a new appliance allows a process of adoption of higherefficiency appliances. In addition, improvements in the energy efficiency of appliances have the potential to decrease households' energy use. Therefore, the rate at which households replace various appliances has important implications for the realization of household energy demand saving in response to technological improvements [18]. The survey results indicate that the average lifetimes of the appliances were similar in the two cities (see Table 2). However, these values are lower than those of developed countries, such as the USA and Canada, where the average lifetime for refrigerators and washing machines is 16 and 12 years, respectively [18].

This difference, however, does not indicate that the adoption of more efficient appliances is more likely in Indonesian households than in the developed countries. Indeed, the values of the standard deviation for most appliances were quite large in both cities. This variation might stem from two sources, technical aspects and cultural aspects. The technical aspects of the problem include several issues. First, the quality of the electrical appliances sold in Indonesia is low. These appliances show low durability. Second, the reliability of the power supply in Indonesia is poor. Due to this quality problem, the electrical appliances are more easily damaged. The cultural aspect of the problem could reflect the way that people use electrical appliances and people's lack of
Table 2. Descriptive statistics of lifetime of appliances.

\begin{tabular}{ccccc}
\hline Appliance & City & N & M & SD \\
\hline \multirow{2}{*}{ TV } & Yogyakarta & 100 & 9.86 & 4.85 \\
& Bandung & 100 & 10.16 & 4.76 \\
Refrigerator & Yogyakarta & 72 & 11.54 & 3.33 \\
& Bandung & 75 & 9.96 & 3.29 \\
Air & Yogyakarta & 10 & 11.10 & 3.11 \\
Conditioner & Bandung & 11 & 12.45 & 2.58 \\
Electric Fan & Yogyakarta & 75 & 5.71 & 3.38 \\
& Bandung & 75 & 7.95 & 2.84 \\
Lighting & Yogyakarta & 100 & 1.56 & 0.79 \\
& Bandung & 100 & 1.25 & 1.16 \\
Rice Cooker & Yogyakarta & 86 & 6.04 & 3.47 \\
& Bandung & 80 & 7.90 & 2.93 \\
& Yogyakarta & 76 & 8.30 & 4.60 \\
Water Pump & Bandung & 50 & 9.80 & 5.58 \\
& Yogyakarta & 41 & 7.71 & 3.73 \\
Machine & Bandung & 38 & 7.68 & 2.31 \\
\hline
\end{tabular}

Note: N stands for Number.

knowledge about operating the appliances. These arguments are strengthened by the respondents' reasons for replacing their appliances (see Figure 1). In the two cities, the most frequent reason to replace an appliance was because it was broken (92\% in Yogyakarta and 97\% in Bandung).

\subsubsection{Required Information on Appliance Characteristics}

The information prior to purchasing an appliance helps

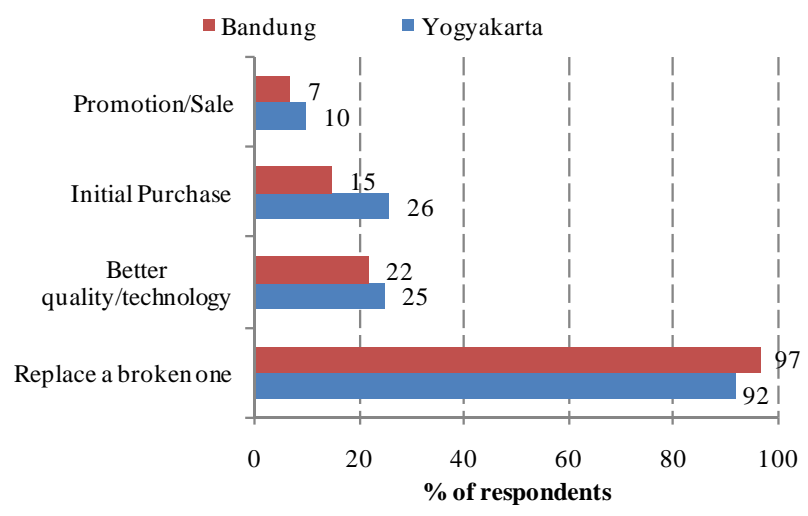

Figure 1. The reasons to replace electrical appliances (because some respondents selected two or more reasons, the totals may exceed $100 \%$ ). 
people make a decision about the purchase of the appliance. The characteristics of appliance including the price, quality, energy consumption, warranty, user friendliness, technology, safety, accessories, type, brand, and country of origin were assessed. The respondents could select more than one answer. The results are shown in Figure 2.

In Yogyakarta, the quality was the most frequently required information and followed by price and brand. Meanwhile, in Bandung, the price was the most frequently required information and followed by quality and warranty. Information related to energy consumption and the technology of the appliance was not a priority for the people in either city. This might be due to a lack of available information on these topics.

In addition, several media were used to access the information that people sought prior to purchasing an appliance (see Figure 3). In Yogyakarta, commercial advertisements in newspapers, magazines, on the Internet or in public spaces were the primary sources of information. In Bandung, most respondents sought information regarding appliance characteristics and used the store's sales staff as a primary source of information.

\subsubsection{Factors that Influence the Purchase of Appliances}

The analysis of the consumer's decision to select the electrical appliance that is most strongly preferred, is

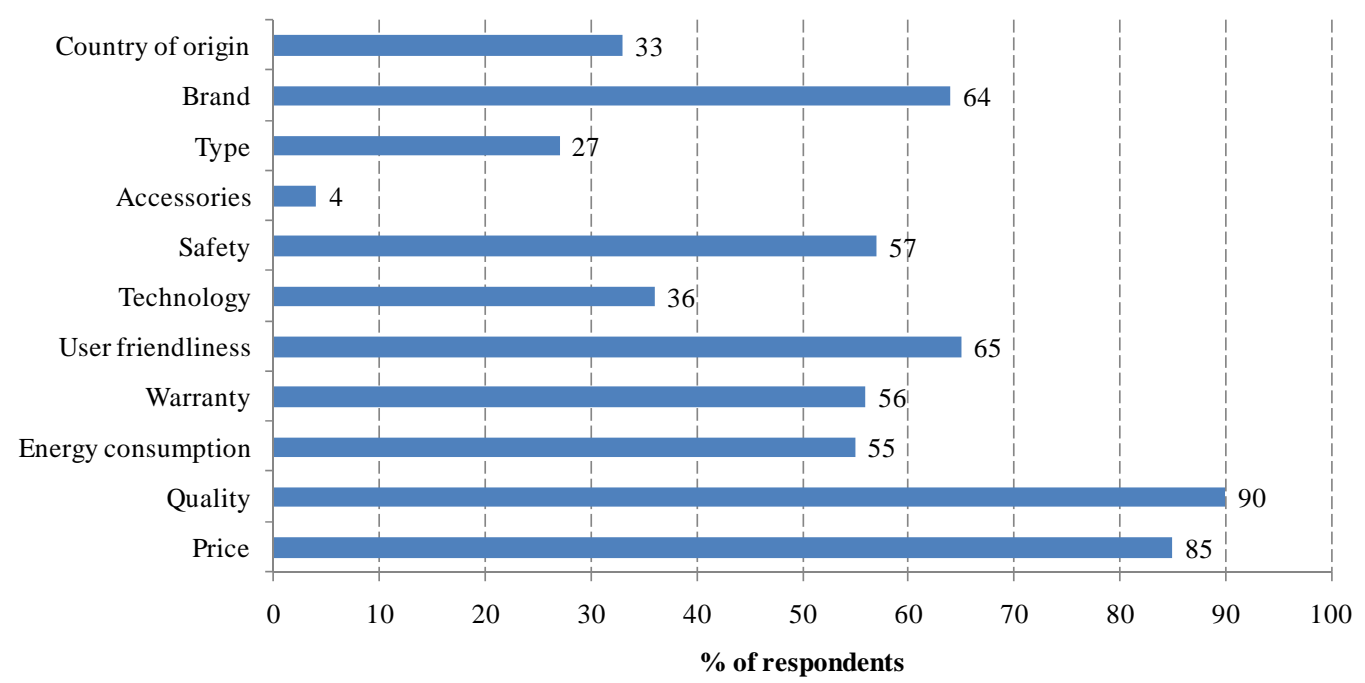

(a)

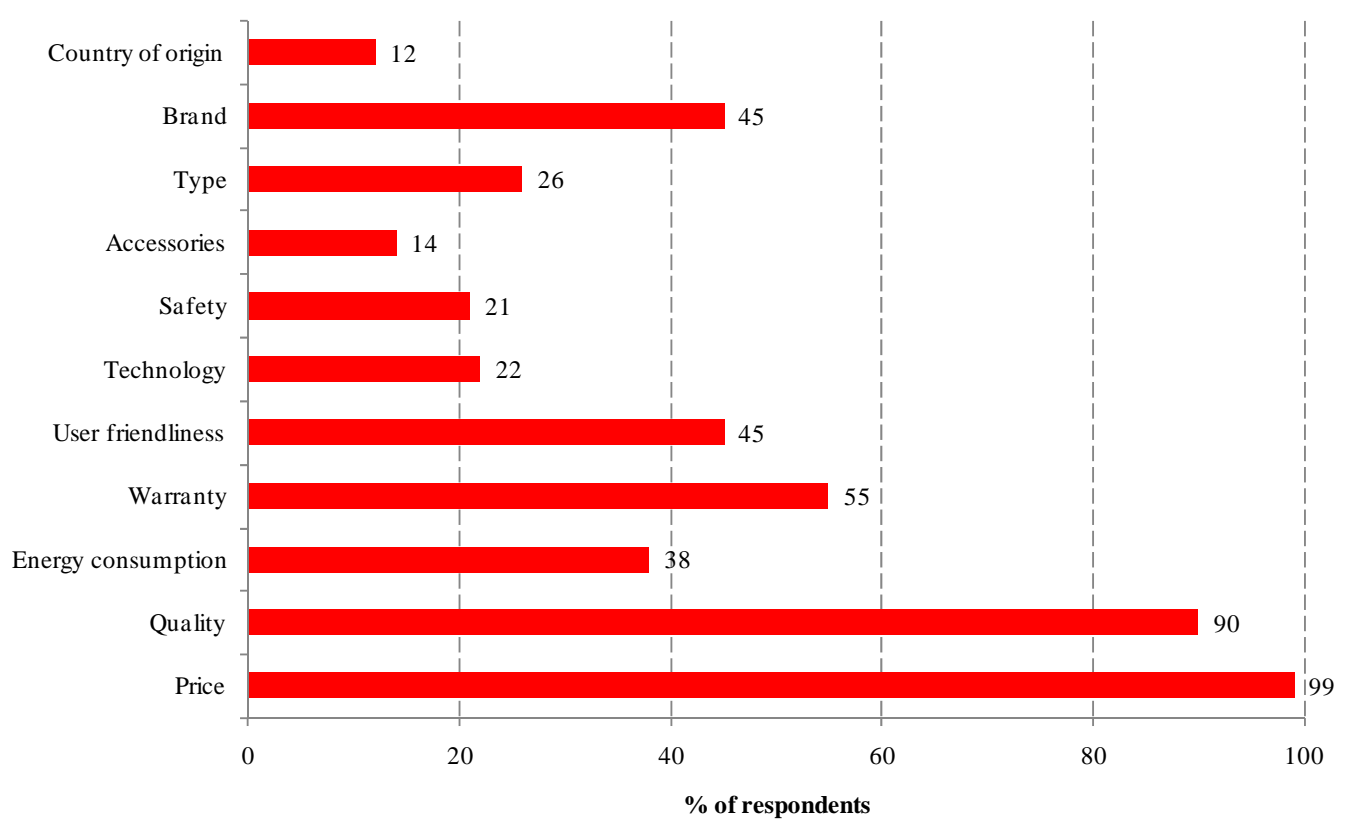

(b)

Figure 2. Required information prior to the purchase of an appliance in (a) Yogyakarta and (b) Bandung. 
important because it reveals the relationship between the factors that influence the purchase of an appliance and the information required prior to purchasing the appliance. By this analysis, a further strategy can be formulated to improve Indonesian households' adoption of higher-efficiency appliances.

The response of respondents indicate that quality, price, safety and energy consumption were the most frequently considered factors in the purchase of an appliance by the respondents in Yogyakarta. In Bandung, the respondents primarily considered price, quality, brand, and user friendliness. Figure 4 shows the respondents' responses on the factors that influence the purchase of appliances in Yogyakarta and Bandung. Table 3 presents a comparison between the two cities on the factors that

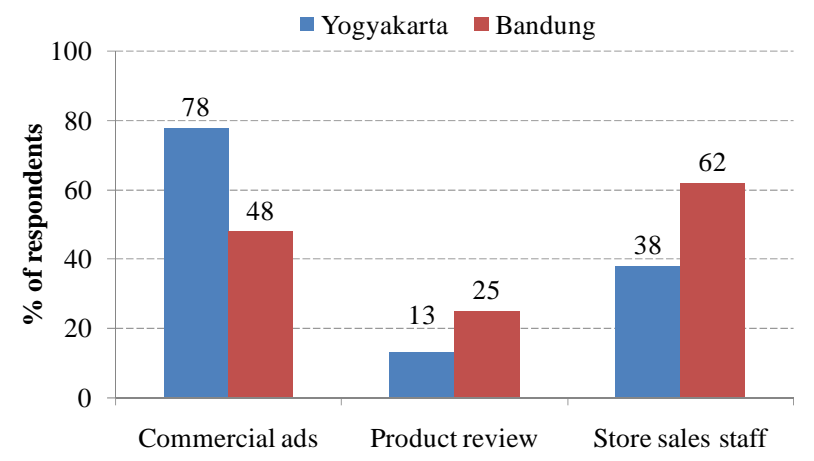

Figure 3. Sources of information prior to purchasing an appliance.

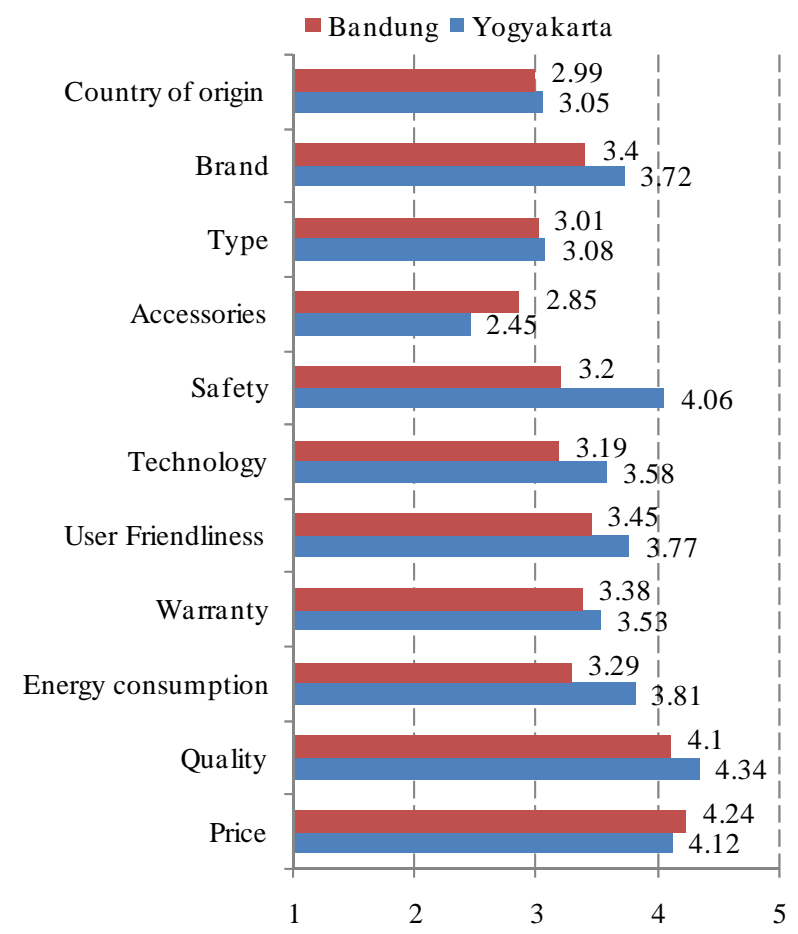

Figure 4. Respondents' response on factors that influence the purchase of appliances. influence the purchase of appliances. A detailed comparison of the responses shows that people in Yogyakarta devoted more attention to considerations of quality, energy consumption, user friendliness, technology, safety, and brand. These results differed significantly from those found in Bandung. People in Bandung devoted more attention to the accessories sold with the appliance.

\subsection{Analysis of Decision-Making in Electrical Appliances Use}

\subsubsection{Understanding of Electricity Price}

In daily life, behavioral economics tend to close relationship with price variable. Therefore, price is often considered to be an important signal in individuals' decision-making concerning electricity consumption [20]. In this survey, the behavioral economics of the respondents in reference to electrical consumption was investigated by questions concerning the following: 1) understanding of the government's electricity prices; 2) memory of their monthly electricity bill (both questions are scaled 1 (not at all) to 4 (highly)); and 3) awareness of the changes in their monthly electricity bill on a scale of 1 (not at all) to 5 (highly). The difference of the point scale in the assessment of awareness of the changes of their monthly electricity bill is more subjective than the two previous questions.

The results, as shown in Table 4, indicate that people in Bandung had a significantly better understanding of electricity prices than people in Yogyakarta. In terms of remembering the monthly electricity bill and awareness of changes in the monthly electricity bill, no significant differences were found between Bandung and Yogyakarta ( $p$-value $>0.05)$.

Table 3. Comparison of influencing factors in the purchase of appliances between Yogyakarta and Bandung.

\begin{tabular}{cc}
\hline Factor & $\boldsymbol{p}$-value \\
\hline Price & 0.19 \\
Quality & 0.02 \\
Energy Consumption & 0.00 \\
Warranty & 0.20 \\
User Friendliness & 0.01 \\
Technology & 0.00 \\
Safety & 0.00 \\
Accessories & 0.00 \\
Type & 0.58 \\
Brand & 0.01 \\
Country of Origin & 0.68 \\
\hline
\end{tabular}


Table 4. Comparison of respondents' understanding of the electricity price between Yogyakarta and Bandung.

\begin{tabular}{|c|c|c|c|}
\hline Question & City & $\mathbf{M}$ & $p$-value \\
\hline \multirow{2}{*}{$\begin{array}{l}\text { How do you understand the } \\
\text { electricity prices }\end{array}$} & Yogyakarta & 2.15 & \multirow{2}{*}{0.02} \\
\hline & Bandung & 2.42 & \\
\hline \multirow{2}{*}{$\begin{array}{l}\text { How do you remember the monthly } \\
\text { electricity bill }\end{array}$} & Yogyakarta & 2.98 & \multirow{2}{*}{0.92} \\
\hline & Bandung & 2.99 & \\
\hline \multirow{2}{*}{$\begin{array}{l}\text { How do you remain aware of } \\
\text { changes in monthly electricity bill }\end{array}$} & Yogyakarta & 3.69 & \multirow{2}{*}{0.09} \\
\hline & Bandung & 3.50 & \\
\hline
\end{tabular}

The results show that electricity prices were not well understood in Yogyakarta and Bandung. By contrast, in terms of remembering the monthly electricity bill, the average response of respondents indicate that people had a good memory of electricity expenditure in both cities (Yogyakarta, Mean $=2.98$ and Bandung, Mean $=2.99$, on a 4-point scale), even though the people in both cities had little knowledge of electricity prices. Similarly, people's awareness of changes in the monthly electricity bill was fair to high in both cities (Yogyakarta Mean = 3.69 and Bandung Mean $=3.50$, on a 5-point scale). These results indicate that the respondents in Yogyakarta and Bandung devoted considerable attention to their monthly electricity expenditure, even though their knowledge of the prices of electricity set by the government was sparse.

These results, linked with the results obtained in subchapters 5.1.2 and 5.1.3, indicate that a lack of understanding of the prices of electricity could be the reason that energy consumption was not selected as the first factor considered in decision-making about the purchase of an appliance in either city. In fact, a component of price that is often overlooked in the purchase of an appliance is the price of the energy consumed by the appliance. If the overall price of the appliance includes an overview of the price of the energy consumed by the appliance during its lifetime, people's awareness of higher-efficiency appliances could be increased significantly. This argument is supported by the results in Table 4. These results show, for both cities, that respondents' awareness was higher for the overall price of the monthly consumption of electricity than the unit price of electricity.

\subsubsection{Electricity Consumed by Appliances}

Electrical appliances consume electricity during use, and electricity costs are calculated based on the amount of electricity consumed by appliances. Hence, knowledge of the power consumed by appliances can be an indication of decision-making in the use of appliances. It is important to note that the rate of power consumed by applian- ces could be a consideration in electrical appliance purchases and use. From this point, respondents in the two cities assessed their awareness of the electricity consumed by the eight appliances (the appliances mentioned in sub-chapter 5.1.1) on a scale of 1 (not at all) to 5 (highly).

The survey results (see Table 5) show that the awareness rate of energy consumed by appliances was significantly higher in Yogyakarta than in Bandung for all appliances except air conditioners ( $p$-value $>0.05$ ). Regarding the frequency of respondents' responses, people in Yogyakarta were concerned with the electricity consumed by the water pump, rice cooker, washing machine and refrigerator (Mean 3.83, 3.76, 3.74 and 3.72, respectively). Figure 5 presents the details of respondents' awareness of the price of electricity consumed by appliances. The people's awareness concerning the water pump and washing machine is because these appliances are considered necessary for daily life and consume a large amount of power. Meanwhile, the rice cooker and refrigerator are always switched on. Overall, the average frequency of respondents' responses to awareness of electricity consumed by appliances is moderate to fair to high for all appliances in both cities.

\subsubsection{Awareness of Energy Efficiency of Appliances}

The efficiency of an appliance influences its electricity consumption; higher rates of efficiency are associated with lower electricity consumption. Therefore, the knowledge and awareness of the energy efficiency of appliances are important in measuring the costs of electricity. The awareness of the energy efficiency of appliances was analyzed to determine whether people utilize this know-

Table 5. Comparison of respondents' responses to various questions between Bandung and Yogyakarta.

\begin{tabular}{cccc}
\hline \multirow{2}{*}{ Appliances } & \multicolumn{3}{c}{ T-test significance (p-value) } \\
\cline { 2 - 4 } & $\begin{array}{c}\text { Awareness of } \\
\text { rate of power } \\
\text { consumed by } \\
\text { appliances }\end{array}$ & $\begin{array}{c}\text { Awareness of } \\
\text { energy } \\
\text { efficiency of } \\
\text { appliances }\end{array}$ & $\begin{array}{c}\text { Response of } \\
\text { change of } \\
\text { electricity } \\
\text { price }\end{array}$ \\
\hline TV & 0.00 & 0.00 & 0.04 \\
Refrigerator & 0.00 & 0.00 & 0.00 \\
$\begin{array}{c}\text { Air } \\
\text { conditioner }\end{array}$ & 0.83 & 0.69 & 0.76 \\
Electric fan & 0.00 & 0.01 & 0.06 \\
Lighting & 0.00 & 0.00 & 0.67 \\
Rice cooker & 0.00 & 0.00 & 0.00 \\
$\begin{array}{c}\text { Water pump } \\
\text { Washing } \\
\text { machine }\end{array}$ & 0.00 & 0.00 & 0.01 \\
\hline
\end{tabular}


ledge in using electrical appliances in their home to reduce the electricity consumption and monthly electricity bill. From the survey in both cities, respondents were asked to rate their awareness of the energy efficiency of eight appliances. The question was scaled from 1 (not at all) to 5 (highly).

The results indicate that, on average, the respondents' awareness was moderate to fair to high for all appliances, with averages above 3 (but less than 4) on the 5-point scale (see details in Figure 6). The survey finds significant differences between the two cities. The awareness rate of energy efficiency was significantly in Yogyakarta than in Bandung for all appliances except air conditioners ( $p$-value $>0.05$ ). The comparison of awareness of energy efficiency of appliances in Bandung and Yogyakarta is shown in Table 5.

From sub-chapter 5.2.2 and 5.2.3, the results indicate

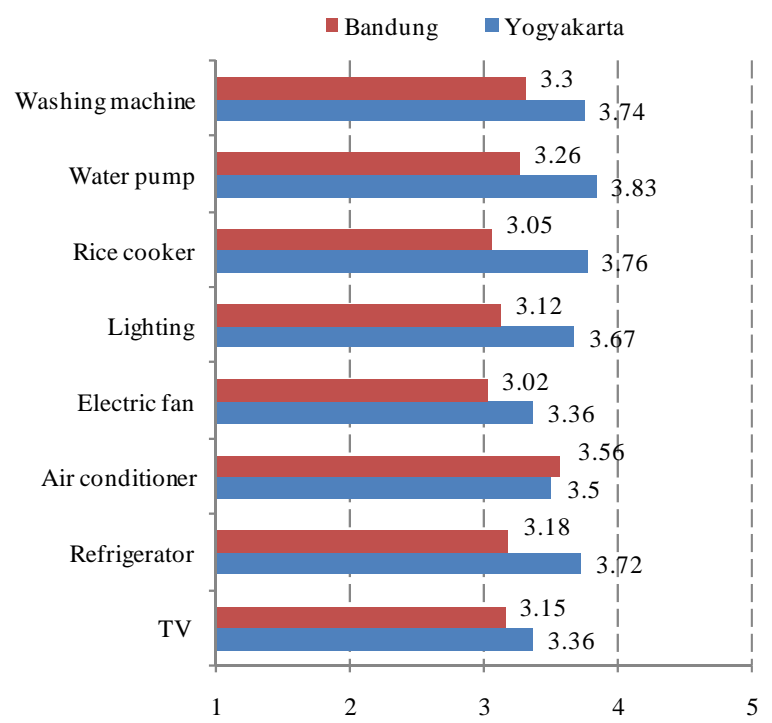

Figure 5. Respondents' awareness of the rate of power consumed by appliances.

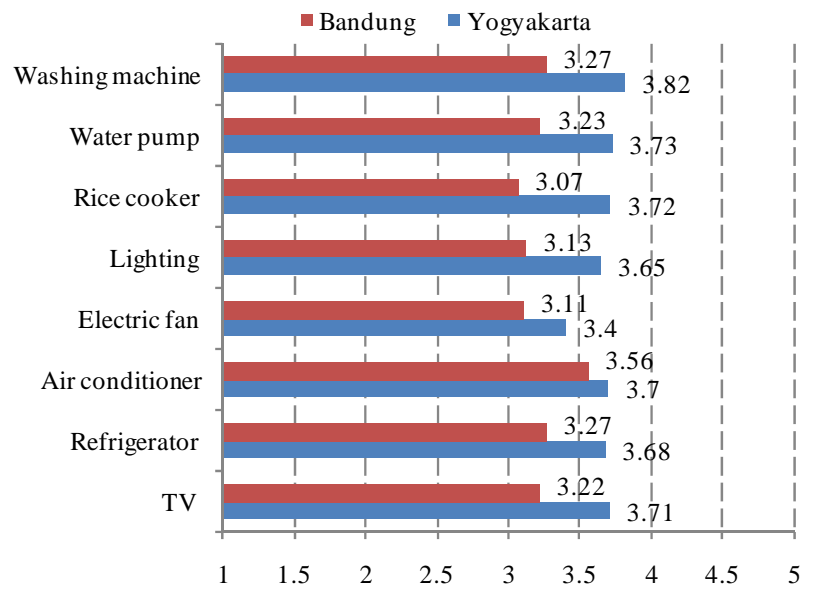

Figure 6. Respondents' awareness of appliances' energy efficiency. that respondents in Yogyakarta give greater attention to electrical appliance use (power consumption and energy efficiency of appliances) than respondents in Bandung. In addition, the results show that awareness of energy efficiency and electricity consumed by appliances could be a decision-making signal for electricity consumption in the home. This result is surprising because energy consumption was not considered as the priority factor in the choice determinants of appliance purchases (as demonstrated in sub-chapter 5.1.3).

\subsubsection{Response to the Change in Electricity Price}

The price is suspected to be an important indicator in decision-making concerning electrical appliance use. Thus, consumers' response to the change in prices was assessed. Respondents in each city were asked how their use of each appliance would change if the current electricity price increased by $10 \%$. The question was scaled from 1 (large decrease) to 5 (large increase).

The results indicate that respondents in Yogyakarta were significantly more likely to reduce their electrical appliance than those in Bandung for TV, refrigerator, rice cooker, water pump, and washing machine. However, no significant differences were found for air conditioner, electric fan and lighting ( $p$-value $>0.05$ ). Details of the comparison of respondents' response to change in electricity prices are presented in Table $\mathbf{5}$. In terms of the average frequency of respondents' response, if the electricity price increased by $10 \%$, the people in Bandung tended not to change their appliance use (all average frequencies of respondents' responses are over 2.5), except for air conditioner use, which was slightly decreased (Mean $=2.19)$. Similarly, respondents in Yogyakarta tended to maintain their normal electricity use, except for air conditioner use (see Figure 7). According to these findings, change in electricity prices did not serve as a signal in decision-making about electricity consumption

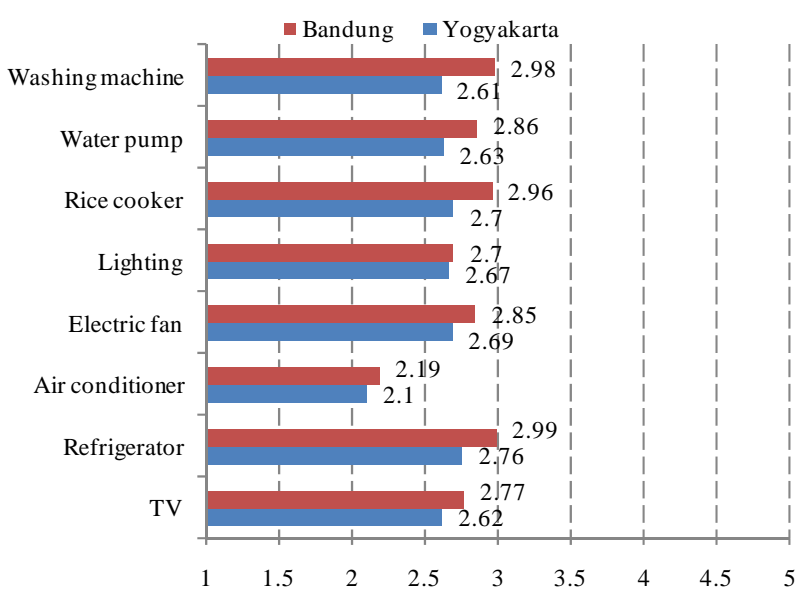

Figure 7. Respondents' responses to change in electricity price. 
in the home.

\subsubsection{Effects of Payment System}

Yamamoto [20] argued that the payment system for home electricity consumption plays an important role in decision-making. Faruqui [22] reviewed 12 pilot studies that investigated the effect of in-home displays that showed electricity use on consumer behavior and found that prepayment metering increased awareness of electricity use. In Indonesia, two payment systems have been enacted, the post-paid system and the prepaid system. With the post-paid system, the consumers are charged a load fee and usage fee. The consumers can view the total amount of electricity use during a month on their bill. Meanwhile, with the prepaid system, the consumer does not pay a load fee, but must purchase a voucher through an Automated Teller Machine or specific designated kiosks for an amount that they select. The prepaid system shows the amount of electricity consumed in real time and the remaining electricity that can be used by the consumer.

The next assessment determined differences in the respondents' awareness of their monthly electricity use based on the prepaid and post-paid systems on a scale of 1 (not at all) to 5 (highly). The results are presented in Table 6. In Yogyakarta, there was no significant difference in respondents' awareness of their electricity payment between the two systems ( $p$-value $>0.05$ ); however, the respondents with the prepaid system displayed greater awareness of electricity payment than respondents with the post-paid system (Mean $=4.23$ and Mean = 4.14, respectively). In Bandung, there was a significant difference between post-paid and prepaid systems ( $p$ value $=0.01)$. Respondents with the post-paid system displayed greater awareness than respondents with the prepaid system; however, the prepaid system (Mean = 3.97) did not guide people to attain greater awareness of electricity consumption than did the post-paid system (Mean $=4.37$ ). In addition, according to the average frequency of responses, both payment systems in Bandung and Yogyakarta served as a signal in decision-making about electricity consumption (Mean of all payment systems $>3.90$ ). These results are in line with the findings in sub-chapter 5.2.1 that people in Bandung and Yogyakarta

Table 6. Comparison of effects of electricity payment.

\begin{tabular}{cccc}
\hline City & Payment system & $\mathbf{M}$ & $\boldsymbol{p}$-value \\
\hline \multirow{2}{*}{ Yogyakarta } & Post-paid & 4.14 & \\
& Prepaid & 4.23 & 0.63 \\
\multirow{2}{*}{ Bandung } & Post-paid & 4.37 & \\
& Prepaid & 3.97 & 0.01 \\
\hline
\end{tabular}

give great attention to monthly electricity expenditure, although the knowledge of government's electricity prices is low.

\section{Policy Implications}

Most policies tend to be designed to affect appliance production and distribution or to influence consumer decision and behaviors [21]. This conventional approach in energy efficiency and energy saving policies should be replaced by a new paradigm that integrates consumer decisions and behaviors within a framework of the local cultures. In this section, a general conceptual policy framework is developed to promote energy conservation in two cities. In addition to the general framework, specific policy based on different indigenous responses is proposed.

\subsection{Conceptual Household Energy Efficiency and Energy Saving Policy Framework for Yogyakarta and Bandung Cities}

As presented in the results and discussion section, a choice determinant in the purchase of electrical appliances and decision-making in the purchase of electrical appliances originate from three internal factors: economic motives (particularly profit and loss reasons), human psychology (awareness, habit, attitude, and norm), and perspective or knowledge of the technology of appliances. Meanwhile, culture indirectly influences the internal factors in making a decision concerning the purchase of electrical appliances or consumption of electricity. Thus, when developing policy, local cultures should be considered as a source of sensitivity. Such consideration will result in the public's wider acceptance of policy

The findings of this study show that policy-makers should utilize differences approaches in two cities to successfully implement energy conservation policy. However, there is a general policy framework that could be implemented in both cities based on the analysis of the respondents' responses. A Conceptual Household Energy Efficiency and Energy Saving Policy Framework (CHE3SPF) has been developed for two cities to show how the policies of energy efficiency and energy saving can result in interventions that aim to manage electricity consumption in the household sector. The CHE3SPF is designed based on the society's perspectives; therefore, the policies input are considered based on the cultural characteristics only. The schematic of the CHE3SPF is presented in Figure 8. Details of the policies that aim to manage electricity consumption in the two cities are presented below:

1) Financial incentives. The price of appliances is the first factor considered prior to purchase; therefore, higher-efficiency appliances should be sold at an affordable 


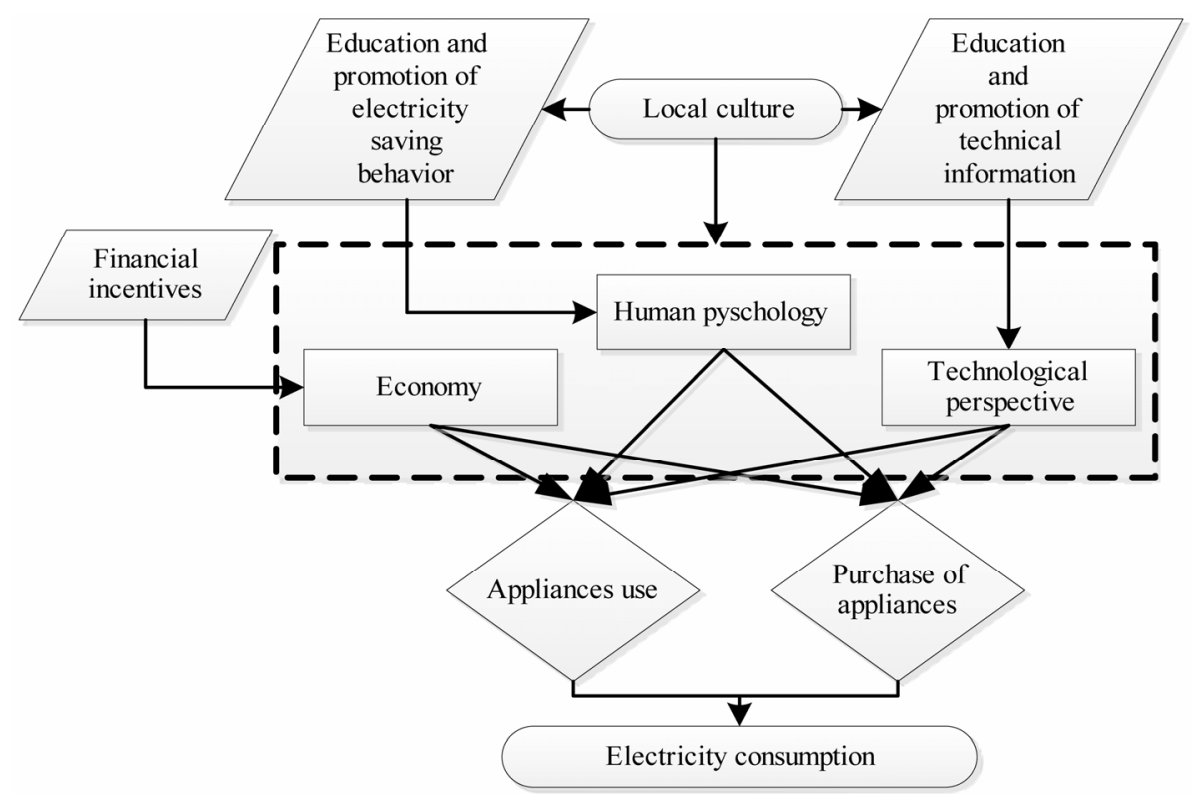

Figure 8. Conceptual Household Energy Efficiency and Energy Saving Policy Framework for both cities.

price. A financial incentive to consumers who are willing to purchase the higher-efficiency appliance class might be required. This policy will attract more people to these appliance types.

2) Education and promotion of technical information. The study found that people's knowledge of electrical appliance use (power consumption and energy efficiency of appliances) could be a signal in decision-making concerning electrical appliances. Therefore, promoting the adoption of high-efficiency appliances is an important way to improve awareness of electricity use.

3) Education and promotion of electricity saving behavior. Technology policies are one of the options available for the reduction of carbon emissions and the usage of energy. However, gains in the efficiency of energy consumption will result in an effective reduction in the per unit price of energy services. As a result, consumption of energy services should increase [23]. In the literature, this impact is often called the "rebound effect of energy efficiency". Doubts have recurrently been raised concerning the extent to which energy efficiency can reduce the demand for energy [24]. The level of the rebound effect for household sectors varies depending on consumer awareness during consumption of appliances. Economy, particularly motivation of profit and loss, is identified as having the greatest influence on the awareness of appliance use. However, based on the current findings, the change in electricity prices policy to increase people's awareness of their electricity consumption and reduce the level of the rebound effect will not result in a significant electricity saving. In the interest of decreasing the rebound effect, Oikonomou [25] integrated several theories in environmental psychology to iden- tify parameters that affect end-use behavior in energy saving and energy efficiency. Although, on average, people in both cities displayed awareness of electricity consumption, the education and promotion of electricity saving behavior must be implemented to foster this habit in all people. This effort is important in combating and anticipating the rebound effect of energy efficiency to enforce the aims of energy conservation.

\subsection{Proposal of Specific Policy Based on Indigenous Response}

Based on the differences in driving factors in choice determinants in the purchase of electrical appliances and decision-making in the purchase of electrical appliances between the two cities, intervention should be tailored with an emphasis on local culture. Therefore, additional extended specific policies from CHE3SPF might be required. The implementation of energy labeling is essential for improving the adoption of higher-efficiency appliances. This scheme might be used in enriching the commercial advertisements with the information related to the energy consumption of appliances, as commercial advertisements play a key role in facilitating the consideration of the purchase of appliances in Yogyakarta. This scheme will increase people's knowledge of the technology within an appliance, particularly related to energy efficiency and energy consumption. The energy labeling scheme has been realized in many countries, such as European Union countries, US, Iran, Brazil, Thailand, Australia and India [26,27], as a key component of efforts to increase the diffusion of energy efficient household appliances. In addition, the energy labeling scheme 
is expected to indirectly improve the quality of appliances sold in domestic market, as the standard of energy labeling requires a minimal efficiency that should be obtained by an appliance.

The specific policies that might be applied for people in Bandung are as follows:

1) An increased implementation of the post-paid system would increase people's awareness of electrical appliance use.

2) In Bandung, the store's sales staff is a primary source of information about appliances. Thus, the sales staff has the greatest impact on people's choice of energy-efficient appliances. Therefore, the policy to provide a regular training for sales staff would result in better penetration of high-efficiency appliance purchases.

\section{Conclusions}

Electricity consumption in Indonesian households with different cultural backgrounds and ethnicities has been studied and analyzed with a case study of Yogyakarta city and Bandung city. The results indicate that in Yogyakarta and Bandung, the quality and price of an appliance are the most important factors considered prior to the purchase and decision-making concerning the purchase. In Yogyakarta, the third factor considered in the decision-making concerning the purchase is energy consumption. However, in Bandung, energy consumption is not a priority factor.

The decision-making concerning electrical appliance use in the home in two cities with different cultural backgrounds has been studied and analyzed. The results show that monthly electricity expenditure and knowledge of electrical appliance use (power consumption and energy efficiency of appliances) could be a signal in decision-making concerning electrical appliances in both cities regardless of the payment system, even though people have little knowledge of the government's electricity prices. The awareness rate of energy consumed by appliances and energy efficiency of appliances is significantly higher in Yogyakarta than in Bandung for all appliances except air conditioners. The results also indicate that if electricity prices increased by $10 \%$, respondents in Yogyakarta are significantly more likely to reduce their electrical appliances use than those in Bandung. However, on average, respondents' would not change their appliance use. This indicates that the change in electricity prices does not serve as a signal in decisionmaking.

Finally, based on these results, a CHE3SPF for both cities has been developed. It illustrates the integration of intervention strategy in the purchase and use of electrical appliances with regard to the consumers' decisions and behaviors within a framework of the local culture to manage electricity consumption in the household sector.
The CHE3SPF aids in developing interventions of choice determinants in the purchase of electrical appliances and decision-making in the use of electrical appliances through economy motives, human psychology, and perspective on the technology of appliances. To address the sensitivity influenced by cultures, several additional specific policies are proposed to improve success in the implementation of energy saving and energy efficiency. These policies are an energy labeling scheme in Yogyakarta city and electricity payment with pre-paid system and training for store sales staff in Bandung city.

Overall, the results of this study have presented a strategy to improve the adoption of higher-efficiency appliances in Indonesia to manage the energy use of households with different cultural backgrounds and ethnicities. For this strategy to succeed, policy improvement and a strong willingness to carry out these strategies are required. A further study that integrates the consumer decision and behaviors in the purchase and use of electrical appliances in the electricity system in the framework of different cultures should be conducted to determine the effectiveness of intervention policies in the future longterm electricity consumption.

\section{Acknowledgements}

This study was funded by the Kyoto University Global Centre of Excellence (GCOE) Program "Energy Science in the Age of Global Warming”. The first author conveys gratitude to the Ministry of Education, Culture, Sports, Science and Technology (MEXT) Japan for providing support during the study.

\section{REFERENCES}

[1] E. Ghisi, S. Gosch and R. Lamberts, "Electricity EndUses in the Residential Sector of Brazil," Energy Policy, Vol. 35, No. 8, 2007, pp. 4107-4120. doi:10.1016/j.enpol.2007.02.020

[2] H. Wilhite, H. Nakagami, T. Masuda, Y. Yamaga and H. Haneda, "A Cross-Cultural Analysis of Household Energy Use Behavior in Japan and Norway,” Energy Policy, Vol. 24, No. 9, 1996, pp. 795-803. doi:10.1016/0301-4215(96)00061-4

[3] A. D. Poyer, L. Henderson and A. P. S. Teotia, "Residential Energy Consumption across Different Population Groups: Comparative Analysis for Latino and Non-Latino Households in USA,” Energy Economics, Vo. 19, No. 4, 1997, pp. 445-463. doi:10.1016/S0140-9883(97)01024-4

[4] K. Genjo, S. Tanabe, S. Matsumoto, K. Hasegawa and H. Yoshino, "Relationship between Possession of Electric Appliances and Electricity for Lighting and Others in Japanese Households,” Energy and Buildings, Vol. 37, No. 3, 2005, pp. 259-272.

doi:10.1016/j.enbuild.2004.06.025

[5] R. Helbert, "Factors Determining Household Fuel Choice 
in Guatemala," Environment and Development Economics, Vol. 10, No. 3, 2005, pp. 337-361. doi:10.1017/S1355770X04001858

[6] C. Wilson and H. Dowlatabadi, "Models of Decision Making and Residential Energy Use," Annual Review of Environment and Resources, Vol. 32, 2007, pp. 169-203. doi:10.1146/annurev.energy.32.053006.141137

[7] R. Kowsari and H. Zerriffi, "Three Dimensional Energy Profiles: A Conceptual Framework for Assessing Household Energy Use,” Energy Policy, Vol. 39, No. 12, 2011, pp. 7505-7517. doi:10.1016/j.enpol.2011.06.030

[8] L. Lutzenhiser, "A Cultural Model of Household Energy Consumption,” Energy, Vol. 19, No. 1, 1992, pp. 47-60. doi:10.1016/0360-5442(92)90032-U

[9] M. E. Wijaya and T. Tezuka, "Understanding Socio-Economic Driving Factors of Indonesian Households Electricity Consumption in Two Urban Areas,” In: T. Yao, Ed., Zero-Carbon Energy Kyoto 2011, Springer, Tokyo, 2012, pp. 56-60. doi:10.1007/978-4-431-54067-0_5

[10] M. E. Wijaya and T. Tezuka, "Measures for Improving the Adoption of Higher Efficiency Appliances in Indonesian Households: An Analysis of Lifetime Use and Decision-Making in The Purchase of Electrical Appliances,” Applied Energy, 2013, in Press. doi:10.1016/j.apenergy.2013.02.036

[11] Statistics Indonesia, “Strategic Data 2010,” 2011. http://www.bps.go.id/ 65tahun/data_strategis.pdf

[12] Center for Data and Information on Energy and Mineral Resources, "Handbook of Energy and Economic Statistics of Indonesia 2010,” 2011. http://prokum.esdm.go.id/Publikasi/Handbook\%20of\%20 Energy\%20\&\%20Economic\%20Statistics\%20of\%20Indonesia\%20/Handbook\%202010.pdf

[13] Statistics Indonesia, “Population Census 2010,” 2011. http://www.bps.go.id/download_file /SP2010_agregat_ data_perProvinsi.pdf

[14] P. T. Perusahaan and L. Negara, "Annual Report 2009: Brightening the Nation in Harmony,” 2010. http://www.pln.co.id/dataweb/AR/ARPLN2009.pdf

[15] Ministry of Energy and Mineral Resources, "National Electricity Master Plan 2008-2027,” 2008, http://prokum.esdm.go.id/kepmen/2008/Kepmen\%20ESD M\%202682\%202008\%20 ZRUKN.pdf

[16] B. Lietaer and S. De Meulenaere, "Sustaining Cultural Vitality in a Globalizing World: The Balinese Example," International Journal of Social Economics, Vol. 30, No. 9, 2003, pp. 967-984. doi:10.1108/03068290310487531
[17] L. Suryadunata, E. N. Arifin and A. Ananta. "Indonesia’s Population: Ethnicity and Religion in Changing Political Landscape,” Institute of Southeast Asian Studies, Singapore, 2003.

[18] D. Young, "When Do Energy-Efficiency Appliances Generate Energy Savings? Some Evidence from Canada," Energy Policy, Vol. 36, No. 1, 2007, pp. 34-46. doi:10.1016/j.enpol.2007.09.011

[19] D. A. Guerin, B. L. Yust and J. G. Coopet, “Occupant Predictors of Household Energy Behavior and Consumption Change as Found in Energy Studies Since 1975," Family and Consumer Science Research Journal, Vol. 19, No. 1, 2000, pp. 48-80. doi:10.1177/1077727X00291003

[20] Y. Yamamoto, A. Suzuki, Y. Fuwa and T. Satu, "Decision-making in Electrical Appliance Use in the Home," Energy Policy, Vol. 36, No. 5, 2008, pp. 1679-1686. doi:10.1016/j.enpol.2008.01.022

[21] R. Gaspar and D. Antunes, "Energy Efficiency and Appliance Purchase in Europe: Consumer Profiles and Choice Determinants,” Energy Policy, Vol. 39, No. 11, 2011, pp. 7335-7346. doi:10.1016/j.enpol.2011.08.057

[22] A. Faruqui, S. Sergici and A. Sharif, "The Impact of Informational Feedback on Energy Consumption: A Survey of the Experimental Evidence,” Energy, Vol. 35, No. 4, 2010, pp. 1598-1608. doi:10.1016/j.energy.2009.07.042

[23] L. A. Greening, D. L. Greene and C. Difiglio, "Energy Efficiency and Consumption: The Rebound Effect-A Survey,” Energy Policy, Vol. 28, No. 6-7, 2000, pp. 389340. doi:10.1016/S0301-4215(00)00021-5

[24] J. Nässén and J. Holmberg, “Quantifying the Rebound Effects of Energy Efficiency Improvements and Energy Conserving Behavior in Sweden,” Energy Efficiency, Vol. 2, No. 3, 2009, pp. 221-231. doi:10.1007/s12053-009-9046-X

[25] V. Oikonomou, F. Becchis, L. Steg and D. Russolillo, "Energy Saving and Energy Efficiency Concepts for Policy Making,” Energy Policy, Vol. 37, No. 11, 2009, pp. 4787-4796. doi:10.1016/j.enpol.2009.06.035

[26] L. Harrington and G. Wilkenfeld, “Appliance Efficiency Program in Australia: Labeling and Standards," Energy and Buildings, Vol. 26, No. 1, 1997, pp. 81-88. doi:10.1016/S0378-7788(96)01015-8

[27] B. Mills and J. Schleich, "What's Driving Energy Efficiency Appliance Label Awareness and Purchase Propensity?” Energy Policy, Vol. 38, No. 2, 2010, pp. 814-825. doi:10.1016/j.enpol.2009.10.028 